\title{
VARIABILITY IN THE ATLANTIC MERIDIONAL OVERTURNING CIRCULATION AND HEAT TRANSPORT DETECTED REMOTELY FROM ARGO FLOATS
}

\author{
Chu, Peter C. ${ }^{1}$, Charles Sun ${ }^{2}$, and Oleg V. Melnichenko ${ }^{3}$ \\ 1) Naval Postgraduate School, Monterey, CA93943, USA \\ (pcchu@nps.edu, tel: 831-656-3688, fax: 831-656-3686) \\ ${ }^{2)}$ NOAA/NODC, Silver Spring, MD 20910, USA \\ ${ }^{3)}$ IPRC, University of Hawaii, Honolulu, HI 96822
}

\begin{abstract}
Available data for ocean temperature, salinity, and current at the present time do not have sufficient resolution to describe the variability in Atlantic Meridional Overturning Circulation (AMOC). To fill the gap, we are working on near real-time $3 \mathrm{D}$ synoptic temperature, salinity, and velocity (STSV) datasets from remotely sensed Argo profiling and trajectory data together with the Global Temperature-Salinity Profile Program (GTSPP), Navy's MOODS, and the OSCAR data using the optimal spectral decomposition (OSD) method. With establishment of the STSV dataset, the AMOC variability can be effectively detected and predicted.
\end{abstract}

Index Terms - Atlantic meridional overturning circulation, Argo float, optimal spectral decomposition, rapid climate change

\section{INTRODUCTION}

The deep-water formation in the Labrador and Nordic seas drives the Atlantic Meridional Overturning Circulation (AMOC). It transports cold deep water southward mainly by the Deep Western Boundary Current (DWBC), and transports warm surface water northward from the southern Atlantic Ocean by the cross-equatorial currents. Changes in the Labrador Cold water formation affect the AMOC and subsequently the sea surface temperature (SST) in the tropics, and in turn cause rapid climate change.

Although the North Atlantic is a subject of intensive theoretical and observational studies for many years, observational support for detecting the AMOC variability is quite poor. This is mainly due to lack of three dimensional ocean data (temperature, salinity, velocity) for the entire Atlantic with sufficient temporal and spatial resolution. Lack of data causes less capability in identifying the AMOC variability. Thus, it is urgent to produce a quality three dimensional dataset for temperature, salinity, and velocity dataset with sufficient spatial resolution $\left(1^{\circ} \times 1^{\circ}\right)$ and temporal resolution (1-3 months) for the entire Atlantic for determining the AMOC variability. The Argo data provides useful information for detecting the AMOC variability. For example, between November 2003 and January 2005, over 56000 float days (cumulative) of data were collected in the North Atlantic $\left(10^{\circ} \mathrm{N}-60^{\circ} \mathrm{N}\right)$ in general at three parking depths: $1000 \mathrm{~m}, 1500 \mathrm{~m}$ and $2000 \mathrm{~m}$. The floats parking at $2000 \mathrm{~m}$, depths shallower than $1000 \mathrm{~m}$, and unknown depths are excluded from the analysis (Fig. 1).

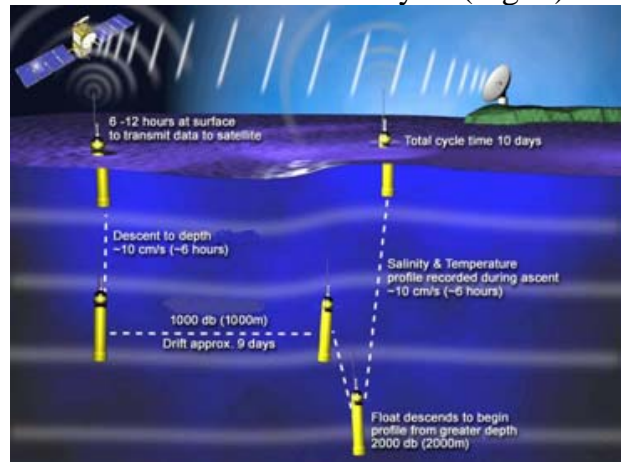

Figure 1. Argo floats for deep ocean measurements (from http://www.argo.ucsd.edu/Frpictures.html).

The optimal spectral decomposition (OSD) method is used to produce 3D temperature, salinity, and velocity fields from the Global Temperature-Salinity Profile Program (GTSPP) and Argo profile and trajectory data since 1990, at spatial resolution higher than the standard product $\left(1^{0} \times 1^{\circ}\right)$. Improvement of temporal and spatial resolution is achieved by merging with data from the Ocean Surface Current Analyses - Real Time (OSCAR) derived from satellite altimeter and scatterometer.

With the reanalyzed three dimensional ocean fields, we may indentify temporal and spatial variability of AMOC and access the current status of AMOC by computing the meridional heat transport. Since rapid changes in AMOC 
could have implications for regional changes of climate, correlation analysis between our reanalyzed datasets (3D ocean fields) and the surface atmospheric data (such as NCEP reanalyzed wind stress, air-ocean heat and moisture fluxes) will improve understanding of the physical mechanisms behind fluctuations in the AMOC. In this paper, we present temporal and spatial variability of middepth ( $1000 \mathrm{~m})$ circulation and heat transport as an illustration.

\section{GTSPP AND ARGO PROFILE DATA}

GTSPP and Argo profile and trajectory data provide great opportunity for determining AMOC variability. Since its inception in 1999 over 30 nations have committed support towards building the Argo array, and a number of other countries have assisted in deploying floats. Deployment of Argo floats started in 2000 and more than 3,000 floats (one float per $3^{\circ} \times 3^{\circ}$ box) surveying the global ocean. Every 10 days, the float pumps fluid into an external bladder and rises to the surface with measuring temperature and salinity. At the surface, the data are transmitted to satellite. The bladder then deflates and float sinks to the depth to drift until the cycle is repeated.

Complexity of GTSPP-Argo profile and trajectory data cause difficulty in retrieving useful information about the AMOC variability. For example, the following sources of uncertainty in Argo float data lead to computational errors in the velocity estimate: (a) the trajectories of Argo floats are not continuous (Fig. 2a); (b) the vertical shear causes an increase or decrease of the real distance between the points of ascending from and descending to the parking depth; (c) the sequence of float trajectory segments (tracks) only approximate the real Lagrangian paths; (d) preliminary computations ${ }^{[1]}$ demonstrated that high resolution elements of mid-depth circulation in the North Atlantic, such as the northern re-circulation gyre in the western North Atlantic, Deep Western Boundary Current (DWBC), the systems of eastward and westward zonal flows in the equatorial Atlantic ${ }^{[2]}$ are also detectable using the Argo float data.

However, such a resolution is not available for the whole North Atlantic and high-energetic mesoscale eddies as well as narrow boundary currents should be classified as "noise" and removed from the analysis or parameterized; (e) there are large spatial gaps (from $200 \mathrm{~km}$ to $600 \mathrm{~km}$ ) in Argo float observation coverage. An interested reader can find the detailed discussion on navigation errors and measurement errors caused by temperature sensors in http://Argo.jcommops.org.

The mid-depth mean velocity (April 2004 to March 2005) can be calculated from the Argo float trajectory data using the bin technique (Fig. 3). The arrows are the mean velocities averaged over appropriate $\left(4^{\circ} \times 4^{\circ}\right)$ bines. The circulation patterns, robust to variations of bin sizes, show well-known circulation features identified from early analyses on the RAFOS float trajectories in separate regions of the North Atlantic.

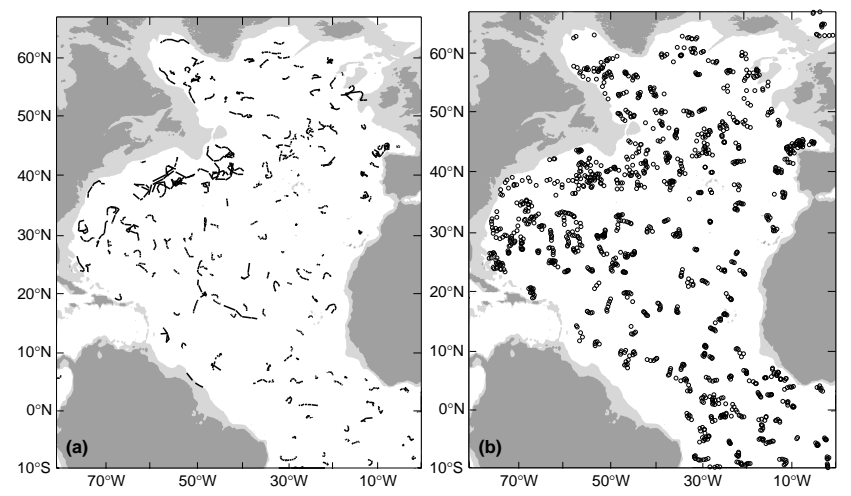

Figure 2. Argo observation coverage of the North Atlantic in October-November, 04: (a) subsurface trajectories of floats parked at $1000 \mathrm{~m}$ and $1500 \mathrm{~m}$, and (b) all float positions where temperature profiles were measured (after Chu et al., 2007). (a)

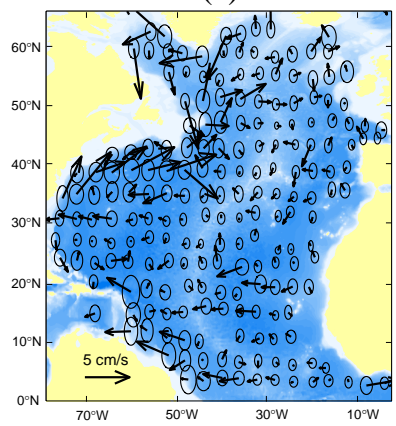

(b)

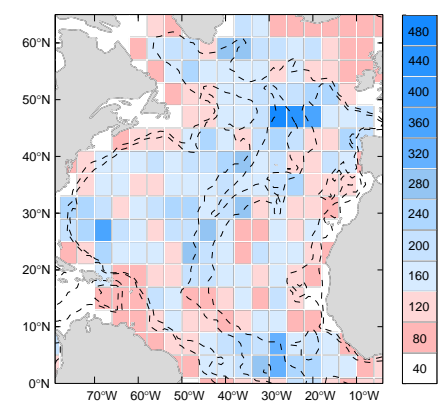

Figure 3. (a) Mean circulations at $\mathbf{1 0 0 0} \mathbf{m}$ depth from April 2004 to March 2005, estimated from the original Argo float trajectories using the bin method (with error ellipses), and (b) data distribution.

\section{OPTIMAL SPECTRAL DECOMPOSITION (OSD)}

Any field (temperature, salinity, or velocity) can be decomposed into generalized Fourier series using the OSD method. The three dimensional field is then represented by linear combination of the products of basis functions (or called modes) and corresponding Fourier coefficients. If a rectangular closed ocean basin is considered, the basis functions are sinusoidal functions. If a realistic ocean basin is considered, the basis functions are the eigen-values of the three-dimensional Laplace operator with real topography. One major benefit of using the OSD method is that the boundary conditions for the ocean variables (temperature, salinity, velocity) are always satisfied.

Following Chu et al. ${ }^{[3][4] ~[5] ~ a ~ v e l o c i t y ~ n o w c a s t ~} \mathbf{U}_{\text {now }}\left(\mathbf{x}_{o}, t\right)$ for quasi-geostrophic currents at any point of the area of interest $\Omega$ is written by the form of parameter-weighted sums of the harmonic $Z_{i}\left(\mathbf{x}_{o}\right)$ and basis $\Psi_{k}\left(\mathbf{x}_{0}\right)$ functions, 


$$
\mathbf{U}_{\text {now }}\left(\mathbf{x}_{0}, t\right)=\sum_{s=1}^{s} a_{s}(t)\left[\mathbf{k} \times \nabla Z_{s}\left(\mathbf{x}_{0}\right)\right]+\sum_{k=1}^{K} b_{k}(t)\left[\mathbf{k} \times \nabla \Psi_{k}\left(\mathbf{x}_{0}\right)\right]
$$

Similarly, a temperature field is represented by a sum of parameter-weighted basis functions $\Xi_{m}\left(\mathbf{x}_{0}\right)^{[5]}$,

$$
T_{\text {now }}\left(\mathbf{x}_{0}, t\right)=T_{c l}\left(\mathbf{x}_{0}\right)+\sum_{m=1}^{M} c_{m}(t) \Xi_{m}\left(\mathbf{x}_{0}\right) .
$$

The spectral coefficients $a_{s}(t), b_{\mathrm{k}}(t), c_{m}(t)$ in Eqs. (3) and (4) are functions of time, $\mathbf{k}$ is the vertical unit vector positive upward, and $\nabla=\left(\nabla_{\varphi}, \nabla_{\lambda}\right)$ is the horizontal gradient operator. $T_{c l}(\mathbf{x})$ is the climatic temperature field from World Ocean Atlas. The harmonic functions $\left\{Z_{i}\left(\mathbf{x}_{o}\right)\right\}$ are the solutions of the horizontal Laplace equation; and the basis functions $\left\{\Psi_{k}\left(\mathbf{x}_{0}\right)\right\}\left\{\Xi_{m}\left(\mathbf{x}_{0}\right)\right\}$ are the solutions of the horizontal Poisson equation with appropriate boundary conditions.

After the harmonic functions $\left\{Z_{i}\left(\mathbf{x}_{o}\right)\right\}$ and basis functions $\left\{\Psi_{k}\left(\mathbf{x}_{0}\right)\right\} \quad\left\{\Xi_{m}\left(\mathbf{x}_{0}\right)\right\}$ are given, the Vapnik variational principle is used to determine the optical spectral truncation $\left(K_{o p t}, M_{o p t}\right)$ in (3) and (4) from a series of velocities $\mathbf{U}_{o b s}^{p}$ computed along Argo float trajectory and temperature observation $T_{o b s}^{p}$ at $\mathbf{x}_{o}^{p}$. The spectral coefficients,

$$
\mathbf{a}=\left[a_{1}, \ldots, a_{s}\right]^{t}, \quad \mathbf{b}=\left[b_{1}, \ldots, b_{K_{\text {or }}}\right]^{t}, \quad \mathbf{c}=\left[c_{1}, \ldots, c_{M_{\text {or }}}\right]^{t},
$$

are estimated using an appropriate variation method. Here, the superscript ' $t$ ' shows the transpose operator. For this study we find that

$$
S=2, K_{\text {opt }}=20, M_{\text {opt }}=38 .
$$

Readers may find detailed description on accuracy of the OSD method from Chu et al. [2007] ${ }^{[1]}$.

\section{MID-DEPTH CIRCULATION}

The reconstructed circulation (April 2004 - March 2005) is characterized by three major cyclonic gyres: tropical (south of $20^{\circ} \mathrm{N}$ ), subtropical $\left(20^{\circ} \mathrm{N}\right.$ to about $50^{\circ} \mathrm{N}$ ), and subpolar gyre (North of $50^{\circ} \mathrm{N}$ ). Fig. 4 shows a sequence of bimonthly snapshots for velocity. The tropical gyre is an elongated cyclonic gyre with velocities in a core of less than $2 \mathrm{~cm} / \mathrm{s}$ and does not correspond to the schematic flow diagram for 500 to $1200 \mathrm{~m}$ proposed by Stramma and Schott [1999]. However, a spatial pattern corresponding to a cyclonic flow approximately around the center of Guinea dome $\left(12^{\circ} \mathrm{N}, 22^{\circ} \mathrm{W}\right)$ is clearly seen in Fig. $4 \mathrm{~b}$. That agrees, for example, with Elmoussaoui et al. [2005] ${ }^{[6]}$ who observed the quasi-permanent cyclonic flow of the Guinea dome at the same depth and deeper.

(a)

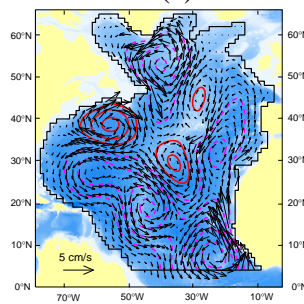

(d)

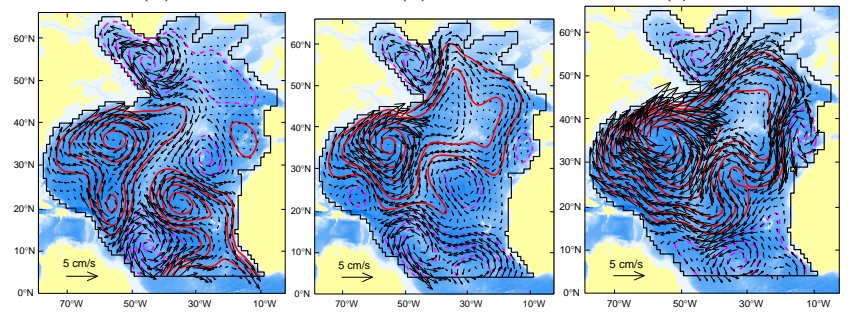

Figure 4. Bi-monthly evolution of circulation at $1000 \mathrm{~m}$ depth for (a) April 2004, (b) June 2004, (c) August 2004, (d) October 2004, (e) December 2004, and (f) February 2005.

For example, the currents flow northwestward near the African coast up to $20^{\circ} \mathrm{N}$ in April and June 2004 (Figs. 4a , b) with maximum speed of about $3 \mathrm{~cm} / \mathrm{s}$, change northward in August 2004 (Fig. 4c), and reverse the direction to southeastward in October 2004 (Fig. 4d). Evidences for this result also can be found ${ }^{[6]}{ }^{[7]}$ and others. Clearly, the reconstructed fields have too lower resolution to be used for the analysis of narrow boundary currents, such as IWBC. Therefore, fall-winter reverses of IWBC from northwestward to southeastward which may be observed south of $15^{\circ} \mathrm{N}^{[2]}$, are not explicitly extracted from our results. However, Chu et al. ${ }^{[1]}$ found the Rossby wave propagation in the tropical North Atlantic using the same Argo trajectory data.

The subpolar gyre of the North Atlantic is a region of complex dynamics, playing a key role in the variability of climate. Its currents are forced by buoyancy contrasts and overflows from neighboring seas, probably as much as by the wind. Because of the low stratification, topography steers the currents, even in the upper layers.

\section{MID-DEPTH HEAT TRANSPORT}

The reconstructed temperature field (April 2004 - March 2005 ) is shown in Fig. 5. Warm water is located in midlatitudes from $8^{\circ} \mathrm{C}$ near western boundary at $25^{\circ} \mathrm{N}-31^{\circ} \mathrm{N}$ to higher than $10^{\circ} \mathrm{C}$ in the eastern boundary at $30^{\circ} \mathrm{N}-50^{\circ} \mathrm{N}$. The warm water was sandwiched by cool water in the low and high latitudes. The temperature is cooler than $4^{\circ} \mathrm{C}$ north of the warm zone.

From the reconstructed monthly velocity $\left(u_{\text {now }}, v_{\text {now }}\right)$ and temperature $\left(T_{\text {now }}\right)$ fields, we compute the horizontal heat flux at $1000 \mathrm{~m}$ depth,

$$
H_{T}=-u_{\text {now }} \partial T_{\text {now }} / \partial x-v_{\text {now }} \partial T_{\text {now }} / \partial y,
$$


with positive (negative) values for warm (cold) advection. Temporal and spatial variability of the horizontal heat flux (Fig. 6) shows evident Rossby wave propagation, which consists with the existing modeling results.

(a)

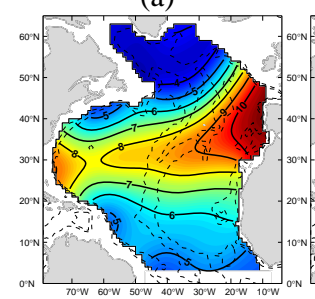

(d)

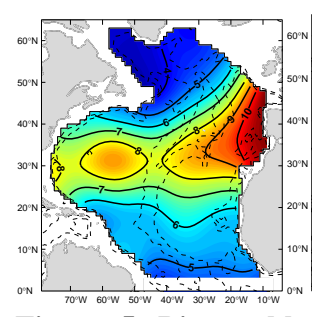

(b)

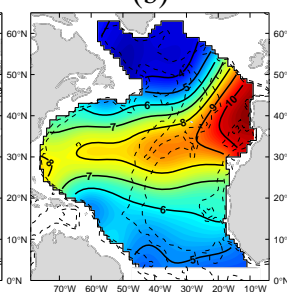

(e)

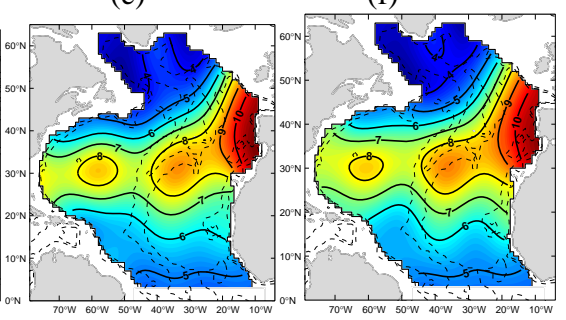

Figure 5. Bi-monthly evolution of temperature at $1000 \mathrm{~m}$ depth for (a) April 2004, (b) June 2004, (c) August 2004, (d) October 2004, (e) December 2004, and (f) February 2005.

These Rossby waves are generated by the reflection of the directly wind driven, shallow Kelvin wave packets at the eastern boundary. These facts show the importance of the Rossby and Kelvin wave dynamics in the inter-annual variability of mid-latitude Atlantic circulation and in teleconnection (linkage) between tropical and mid-latitude inter-annual variability.

(a)

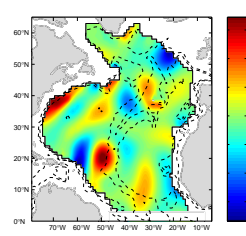

(d)

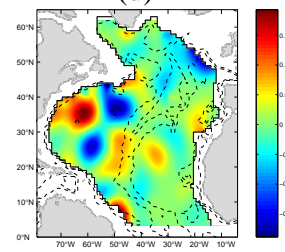

Figure 6. Bi-monthly evolution of horizontal heat flux, HT ( $\left.{ }^{\circ} \mathrm{C} / \mathrm{month}\right)$ at $1000 \mathrm{~m}$ depth for (a) April 2004, (b) June 2004, (c) August 2004, (d) October 2004, (e) December 2004, and (f) February 2005.

\section{CONCLUSIONS}

Establishment of near-real time 3D synoptic temperature, salinity, and velocity (STSV) datasets using the OSD method from GTSPP-Argo, Navy's MOODS, and OSCAR with higher resolutions and better coverage than any products available, temporal (seasonal and inter-annual) and spatial (various scales) variability of AMOC can be identified through quantifying the derived variables such as the meridional overturning (MO) streamfunction, heat storage, meridional heat transport, etc.. The physical mechanisms causing the AMOC variability can be determined through correlation analysis between the STSV data (including derived variables) and surface atmospheric data or investigation of the role of long baroclinic Rossby waves (longer than $500 \mathrm{~km}$ ) generated in the eastern Atlantic on the AMOC variability.

\section{ACKNOWLEDGMENTS}

This research was supported by the NOAA/NODC, Office of Naval Research, Naval Oceanographic Office, and Naval Postgraduate School.

\section{REFERENCES}

[1] P.C. Chu, L.M. Ivanov, O.V. Melnichenko, and N.C. Wells, "On long baroclinic Rossby waves in the tropical North Atlantic observed from profiling floats," Journal of Geophysical Research, 112, C05032, doi:10.1029/2006JC003698, 2007.

[2] L. Stramma, and F. Schott, "The mean flow of the tropical Atlantic Ocean,” Deep Sea Research, 46, 279-303, 1999.

[3] P.C. Chu, L.M. Ivanov, T.M. Margolina, T.P. Korzhova, and O.V. Melnichenko, "Analysis of sparse and noisy ocean current data using flow decomposition. I. Theory,” Journal of Atmospheric and Oceanic Technology, 20, 478 - 491, 2003a.

[4] P.C. Chu, L.M. Ivanov, T.M., Margolina, T.P. Korzhova, and O.V. Melnichenko, “ Analysis of sparse and noisy ocean current data using flow decomposition. Part 2. Applications to Eulerian and Lagrangian data," Journal of Atmospheric Oceanic Technology, 20, 492-512, 2003b. [5] P.C. Chu, L.M. Ivanov, and T.M. Margolina, "Rotation method for reconstructing process and fields from imperfect data.," International Journal of Bifurcation and Chaos, 14 (8), 2991-2997, 2004.

[6] A. Elmoussaoui, M. Arhan, M., and M. Treguier, A.M., "Model-inferred upper ocean circulation in the eastern tropics of the North Atlantic," Deep Sea Research, 52, 1093-1120, 2005.

[7] D.M. Fratantoni, and P.L. Richardson, "SOFAR float observations of an intermediate-depth eastern boundary current and mesoscale variability in the eastern Tropical Atlantic Ocean,” Journal of Physical Oceanography, 29, 1265-127, 1999. 